$4-2016$

Providing care beyond the hospital: Perspective of a tertiary care hospital from a developing country

Saad Akhtar

Muhammad Waqas

Badar Uddin Ujjan

Adnan Salim

Gohar Javed

See next page for additional authors

Follow this and additional works at: https://ecommons.aku.edu/pakistan_fhs_mc_surg_neurosurg

Part of the Neurology Commons, Neurosurgery Commons, and the Surgery Commons 


\section{Authors}

Saad Akhtar, Muhammad Waqas, Badar Uddin Ujjan, Adnan Salim, Gohar Javed, Syed ljlal Ahmed, Malikah Surani, and Marium Khan 


\title{
Providing Care Beyond the Hospital: Perspective of a Tertiary Care Hospital from a Developing Country
}

\author{
Saad Akhtar Khan ${ }^{1}$, Muhammad Waqas ${ }^{1}$, Badar Uddin Ujjan ${ }^{1}$, Adnan Salim², Gohar Javed ${ }^{1}$, Syed ljlal Ahmed ${ }^{1}$, \\ Malikah Surani ${ }^{1}$, Marium Khan ${ }^{1}$
}

\begin{abstract}
BACKGROUND: Neurorehabilitation is an important aspect of continuing care for neurosurgical patients with functional disability. In developing countries, where formal home nursing frequently is unavailable, ensuring care after discharge is a difficult task. Training attendants to provide nursing care is an alternate option. In this study, we compared the outcomes of patients nursed by family members versus those looked after by a professional nurse.
\end{abstract}

METHODS: This was a retrospective observational study conducted at the Aga Khan University Hospital Karachi. The study consisted of 2 groups. Group 1 (consisting of patients cared for by a professional nurse) included 94 patients and group 2 (patients cared for by family members) included 102. All these patients had activity of daily living score of $\geq 3$. Glasgow Outcomes Scale score, time to decannulation, development/worsening of bedsores, and mortality were recorded and compared between the groups at follow-up.

RESULTS: The study included 196 patients. Traumatic brain injury was the most common diagnosis. Nursing requirements were similar between the 2 groups and included tracheostomy care, percutaneous endoscopic gastrostomy tube care, peripherally inserted central catheter line care, care of patients with no bone flap, and log-rolling. The outcomes of the 2 groups were comparable and included bedsore development/ worsening of grade, Glasgow Outcomes Scale score at follow-up, time to decannulation, and 30-day mortality.
CONCLUSIONS: There was no statistically significant difference in outcomes of patients nursed by family members compared with the patients looked after by professional nurses.

\section{INTRODUCTION}

T eurorehabilitation is an important aspect of continuing care for neurosurgical patients with functional dependence. Long-term quality nursing care is critical to the achievement of optimal outcomes in such patients. In developing countries, this aspect of management often is overlooked and studied inadequately. This is a multifaceted problem that includes several factors, such as lack of awareness among general population, financial constraints, and lack of an integrated health care system. Most of the developing countries including Pakistan lack institutes for the rehabilitation of patients with functional dependence or diseases that need specialized nursing care. As one of the leading centers of clinical neurosciences in the country, we are faced with a challenge of providing adequate care and rehabilitation once these patients are discharged to ensure achievement of optimal neurologic recovery and surgical outcomes.

Training attendants to be caregivers is an alternate option that has been studied, especially in the context of end-of-life care. Attendants are taught nursing care, and once adequately trained, take over the role of a professional nurse. This alternate option ensures nursing care at home when professional nurses cannot be hired or afforded. There have been studies on patients suffering from chronic illnesses that suggest that home care is cheaper compared with hospital or nursing home $\operatorname{car}^{\mathrm{I}-6}$; however, some

\section{Key words \\ - Disability \\ - Neurosurgery \\ Nursing \\ - Rehabilitation}

Abbreviations and Acronyms

GOS: Glasgow Outcome Scale

PCC: Patient care coordinator

PEG: Percutaneous endoscopic gastrostomy

TBI: Traumatic brain injury
From the ${ }^{1}$ Section of Neurosurgery, Department of Surgery, The Aga Khan University Hospital, Karachi; and ${ }^{2}$ Dow Medical College, Dow University of Health Sciences, Karachi, Pakistan

To whom correspondence should be addressed: Dr. Gohar Javed.

[E-mail: gohar.javed@aku.edu]

Citation: World Neurosurg. (2016) 88:370-373.

http://dx.doi.org/10.1016/j.wneu.2015.12.086

Journal homepage: Www.WORLDNEUROSURGERY.org

Available online: www.sciencedirect.com

1878-8750/\$ - see front matter ๔ 2016 Elsevier Inc. All rights reserved. 
researchers suggest that the cost of home care is greater if family labor is included. . $^{\text {-10 }}$

There are limited data that compare outcomes of neurosurgery patients cared for by professional nurses compared with those cared for by trained family members. Therefore, we decided to look at our own data to assess the difference in the 2 groups. The objective of this study was to compare the 2 groups on parameters that reflect the quality of nursing care.

\section{METHODS}

This was a retrospective cohort study conducted at Aga Khan University Hospital over a period of 5 years (2009-2014). Aga Khan University Hospital is a Joint Commission International Accreditation-accredited tertiary care referral center and a teaching hospital with well-established neurology and neurosurgery units.

We included adult neurosurgery patients ( $16-70$ years) with activity of daily living score of $\geq 3$ who needed nursing care at home irrespective of sex or pathology. Patients who were looked after by both nursing and family members simultaneously or at different times were excluded. We also excluded patients with a follow-up of less than I month and those who received nursing care at other hospitals after discharge.

Data were collected through a proforma report. Variables such as age, sex, comorbidities, presenting diagnosis, presenting Glasgow Coma Scale score, procedure performed, severity of deficit, stay in the intensive care unit, type of home nursing care provided (trained attendant or professional nurse), and Glasgow Outcome Scale (GOS) at discharge were recorded. Nursing parameters studied were tracheostomy care, feeding via percutaneous endoscopic gastrostomy (PEG), bedsore care, and administration of intravenous antibiotics. Outcome assessments were obtained, including GOS at follow-up, time to decannulation, development/worsening of bedsores, and mortality.

At our institute, neurosurgical patients with a major deficit (defined as one due to which the patient cannot perform routine activity independently) and functional dependence are identified during hospital stay and options of home nursing are discussed with family. Nursing care required at home and support system are identified by the patient care coordinator (PCC). The family decides the type of nursing (trained attendant or professional nurse). The option of training a family member was initiated by identifying a family member. The family member was then trained in basic nursing and rehabilitation by the nursing and physiotherapy team. Family members were trained for basic tracheostomy care, nasogastric/PEG feeding, chest and limb physiotherapy, and bedsore and basic urinary catheter care. Nursing care was started before discharge by both groups of caregivers. Quality of care given by both group was assessed by the PCC during his/her rounds and the patient was discharged once the PCC and the primary attending found the care provided satisfactory. GOS at discharge was noted. Patients were discharged and followed in clinic, and feedback was taken regarding the nursing care; quality of care given was further assessed on follow-up. Outcomes including time to decanulation, bedsore development, mortality, and GOS at follow-up were compared.

Categorical data were described with frequencies and percentages. Continuous data with normal distribution were reported as mean and SD, and skewed data were presented as median and ranges. Categorical variables were compared between the 2 groups with the $\chi^{2}$ test whereas the independent $t$ test was used for continuous data. A P-value of less than 0.05 was considered significant. The data were analyzed using SPSS version 17 (SPSS Inc., Chicago, Illinois, USA).

\section{RESULTS}

The number of patients included in this study was ig6. They were divided in 2 groups at discharge based on type of nursing care provided. Group I consisted of patients who were looked after by professional nursing staff $(n=94)$, whereas Group 2 included I02 patients who were taken care by trained family members. A total of $77 \%$ had traumatic brain injury (TBI), 7.I \% had tumors, and $12.2 \%$ presented with vascular lesions (such as arteriovenous malformations and aneurysms). A total of $22.4 \%$ had hypertension and 7.I \% had diabetes mellitus. In patients with TBI, 38.8\% had contusion, $5.1 \%$ had diffuse axonal injury, and $17.9 \%$ had intracranial/intraventricular hemorrhage. A total of $19 \%$ of the patients who could be assessed had major focal deficits. Demographics and clinical characteristics of patients in each group were comparable and are presented in Table 1.

At the time of discharge, $34.7 \%$ of patients required tracheostomy care, $23 \%$ needed PEG tubes feeding and care, whereas $18.4 \%$ had a peripherally inserted central catheter line. Intravenous antibiotics were required by $40.3 \%$ and log rolling by $5 \mathrm{I} .5 \%$. Nursing requirements were similar between the 2 groups and included tracheostomy care, PEG tube care, peripherally inserted central catheter line care, care of patients with no bone flap, and log-rolling (Table 1).

The outcomes of the 2 groups were comparable and included bedsore development/worsening of grade, GOS at follow-up, time to decanulation, and 30-day mortality. These results are presented in Table 2. In Group I, I7 patients had died at follow-up compared to 13 in group 2; however, the P value was not statistically significant. The number of vegetative patients in each group also was comparable ( 23 and I7, respectively); 9I.3\% patients had at least I year of follow-up.

\section{DISCUSSION}

Neurosurgery deals with some of the most devastating illnesses in the form of TBI, cerebral infections, and brain tumors. Despite all the advancements in basic and clinical neurosciences, most of these conditions carry significant morbidity, mortality, and functional impairments. According to estimates, 5.3 million people are living with TBI-related disability alone. ${ }^{\text {II }}$ Similarly, up to $78 \%$ of patients with brain tumors may have motor deficits. ${ }^{\text {I2 }}$ According to a report, 127 million Europeans are living with a brain disorder in a population of 466 million. ${ }^{13}$ The total annual cost of brain disorders in Europe was estimated to $386 €$ billion in 2004. ${ }^{13}$ Although the reported proportion of patients suffering from neurosurgical disorders in that study was small, nursing care requirements of patients with disability due to brain disorder do not differ significantly.

Neurorehabilitation is therefore a vital component of long-term management of these patients. In 1995, there were 16,700 nursing homes nationwide with $\mathrm{I} .5$ million residents in United States. Strahan et al. reported a $9 \%$ increase in number of beds during the 
Table 1. Demographic and Clinical Characteristic and Nursing Care Requirements of Study Population

\begin{tabular}{|c|c|c|c|}
\hline Variables & $\begin{array}{l}\text { Trained } \\
\text { Nursing } \\
\text { (Group1) }\end{array}$ & $\begin{array}{l}\text { Family } \\
\text { Members } \\
\text { (Group 2) }\end{array}$ & $P$ Value \\
\hline Age & 38.49 & 31.16 & 0.008 \\
\hline Male, \% & 78 & 74 & 0.24 \\
\hline LOS & 25.62 & 19.67 & 0.097 \\
\hline \multicolumn{4}{|l|}{ Diagnosis } \\
\hline Trauma & 80 & 73 & \\
\hline Tumor & 8 & 6 & \\
\hline Vascular & 6 & 18 & \\
\hline \multicolumn{4}{|c|}{ GCS score at the time of admission } \\
\hline $13-15$ & 10 & 14 & \multirow[t]{3}{*}{0.242} \\
\hline $9-12$ & 28 & 20 & \\
\hline $3-8$ & 56 & 58 & \\
\hline \multicolumn{4}{|l|}{ Procedure } \\
\hline Decompressive craniectomy & 30 & 21 & \multirow[t]{3}{*}{0.001} \\
\hline Craniotomy & 40 & 26 & \\
\hline Laminectomy & 2 & 2 & \\
\hline \multicolumn{4}{|l|}{ Comorbidity } \\
\hline HTN & 18 & 14 & \multirow[t]{6}{*}{0.166} \\
\hline Diabetes & 0 & 2 & \\
\hline HTN + diabetes & 4 & 8 & \\
\hline CRF & 2 & 0 & \\
\hline Other & 4 & 6 & \\
\hline None & 60 & 70 & \\
\hline Major focal deficits & 15 & 22 & 0.414 \\
\hline \multicolumn{4}{|l|}{ GOS at the time of discharge } \\
\hline 2 & 23 & 17 & \multirow[t]{4}{*}{0.397} \\
\hline 3 & 33 & 35 & \\
\hline 4 & 31 & 37 & \\
\hline 5 & 7 & 13 & \\
\hline \multicolumn{4}{|l|}{ Nursing care } \\
\hline Trach tube & 36 & 32 & 0.522 \\
\hline PEG & 20 & 25 & 0.591 \\
\hline Log roll & 54 & 47 & 0.082 \\
\hline PICC & 22 & 14 & 0.080 \\
\hline No bone flap (DEC CRANI) & 30 & 21 & \\
\hline $\begin{array}{l}\text { LOS, length of stay; GCS, Glasgow } \\
\text { failure; GOS, Glasgow Outcome } \\
\text { PICC, peripherally inserted centr }\end{array}$ & $\begin{array}{l}\text { Scale; HTN } \\
\text {; PEG, percu } \\
\text { heter; DEC C }\end{array}$ & $\begin{array}{l}\text { pertension; CR } \\
\text { eous endoscop } \\
\text { l, decompressi }\end{array}$ & $\begin{array}{l}\text { ronic renal } \\
\text { strostomy; } \\
\text { aniectomy. }\end{array}$ \\
\hline
\end{tabular}

Table 2. Differences in Outcomes Between the 2 Groups

\begin{tabular}{|c|c|c|c|}
\hline Variables & Group 1 & Group 2 & $P$ Value \\
\hline Time to decanulation, days & 23.29 & 19.69 & \\
\hline \multicolumn{4}{|l|}{ GOS at follow-up } \\
\hline 1 & 17 & 13 & \multirow[t]{5}{*}{0.020} \\
\hline 2 & 3 & 3 & \\
\hline 3 & 8 & 13 & \\
\hline 4 & 22 & 31 & \\
\hline 5 & 44 & 42 & \\
\hline Mortality & 17 & 13 & 0.300 \\
\hline \multicolumn{4}{|l|}{ Bed sores } \\
\hline Absent & 46 & 62 & \\
\hline Grade I & 8 & 12 & \\
\hline Grade II & 8 & 6 & \\
\hline Grade III & 2 & 2 & \\
\hline Grade IV & 2 & 2 & \\
\hline
\end{tabular}

past Io years. ${ }^{\text {4, I5 }}$ There are several obstacles to providing longterm nursing care in developing countries, like Pakistan, which, according to the World Bank Report, is a low middle-income country. The concept of nursing homes is nascent and as a result, long-term arrangements of nursing care are difficult. Therefore, educating and training family members to take care of these patients becomes essential.

Many studies have demonstrated that home care is cheaper and more favorable than institutional care for patients with chronic illnesses. ${ }^{1,6,16}$ This study explores this important aspect of management of these patients at a single private hospital in a developing country. Contrary to the results from previous studies, our study did not show any difference in outcomes between the 2 groups.

We observed no significant difference in outcomes between the 2 groups; however, there is a great unmeasured economic burden and psychological stress on family who take care of their functionally dependent relatives. This factor, although important, was not studied by us; however, several previous studies has addressed this topic. ${ }^{9,17-23}$

To the best of our knowledge, this is the first study on this subject from this region. It highlights the importance of long-term nursing care and lack of adequate facilities. We also highlight that trained family members can care adequately for these patients; however, the apparent burden of such arrangement needs to be weighed against the potential benefits.

The most important caveat is the retrospective design with all its inherent pitfalls. Because of a lack of detailed documentation, an extensive scoring system measuring functional status and outcomes could not be applied; however, we had sufficient information to apply GOS and adequately assess nursing care related parameters. 


\section{CONCLUSIONS}

Long-term nursing care and rehabilitation is an important aspect in management of neurosurgical patients, and where professional nurses or nursing homes are not available, family members can be trained for providing comparable nursing care; however, investigations into to the economic and emotional implications of such arrangement are necessary. Such studies can guide authorities in designing and implementing health care system.

\section{REFERENCES}

I. Chiu L, Shyu WC, Liu YH. Comparisons of the cost-effectiveness among hospital chronic care, nursing home placement, home nursing care and family care for severe stroke patients. J Adv Nurs. 200I;33:380-386

2. Nielsen LJ, Blenkner M, Bloom M. Older persons after hospitalization; a controlled study of home aids services. Am J Public Health. I972;62:I094-IIor.

3. Mitchell JB. Patient outcomes in alternative longterm care setting. Med Care. I978;16:439-445.

4. Clarfield AM. Home care: is it effective? Can Med Assoc J. I983;I29:II8I-II84.

5. Wolinsky FD, Arnold CL. A different perspective on health and health services utilization. Annu Rev Gerontol Geriatr. I988;8:7I-IoI.

6. Wu SC, Chu CM. Public attitudes toward longterm care arrangements for the elderly: findings from social image survey. Chinese J Public Health (Taipei). 1995;14:369-382 [in Chinese].

7. Jacobs P, McDermott S. Family caregiver costs of chronically ill and handicapped children: method and literature review. Public Health Rep. I989;I04: I58-167.

8. Stommel M, Given CW, Given BA. The costs of cancer home care to families. Cancer. I993;7I: I876-I884.

9. Chiu L, Tang KY, Liu YH, Shyu WC, Chang TP. Cost comparisons between family-based care and nursing home care for dementia. J Adv Nurs. I999; 29:IOO5-IOI2.
Io. Pitsenberger DJ. Juggling work and elder caregiving work-life balance for aging American workers. AAOHN J. 2006;54:I8I-I85.

II. Thurman D, Alverson C, Dunn K, Guerrero J, Sniezek J. Traumatic brain injury in the United States: a public health perspective. J Head Traum Rehabil. I999;I4:602-615.

I2. Mukand JA, Blackinton DD, Crincoli MG, Lee J, Santos BB. Incidence of neurologic deficits and rehabilitation of patients with brain tumors. Am J Phys Med Rehabil. 200I;80:346-350.

13. Andlin-Sobocki P, Jönsson B, Wittchen HU, Olesen J. Cost of disorders of the brain in Europe. Eur J Neurol. 2005;I2(Suppl I):I-27.

I4. Strahan GW. An overview of nursing homes and their current residents: data from the 1995 National Nursing Home Survey. Advance data from vital and health statistics; no. 280. Hyattsville, MD: National Center for Health Statistics; 1997

55. Wolff J, Boult C, Boyd C, Anderson G. Newly reported chronic conditions and onset of functional dependency. J Am Geriatr Soc. 2005;53:85I-855.

I6. Sorrell JM. Caring for the caregivers. J Psychosoc Nurs Ment Health Serv. 2007;45:17-20.

I7. Stajduhar KI. Examining the perspectives of family members involved in the delivery of palliative care at home. J Palliat Care. 2003;19:27.

I8. Martire LM, Lustig AP, Schulz R, Miller GE, Helgeson VS. Is it beneficial to involve a family member? A meta-analysis of psychosocial interventions for chronic illness. Health Psychol. 2004;23:599-6II.
I9. Garity J. Caring for a family member with Alzheimer's disease: coping with caregiver burden post-nursing home placement. J Gerontol Nurs. 2006;32:39-48.

20. McKenna H, Ryan A, Fleming P. The experience of the family caregivers' role: a qualitative study. Res Theory Nurs Pract. 2003;I7:I37-I5I.

2I. Penrod J, Hupcey JE, Shipley PZ, Loeb SJ, Baney B. A model of caregiving through the end of life: seeking normal. West J Nurs Res. 2012;34:I74-I93.

22. Stevenson JP. Family stress related to home care of Alzheimer's disease patients and implications for support. J Neurosci Nurs. I990;22:I79-I88.

23. McCorkle R, Benoliel JQ, Donaldson G, Georgiadou F, Moinpour C, Goodell B. A randomized clinical trial of home nursing care for lung cancer patients. Cancer. I989;64:I375-I382.

Conflict of interest statement: The authors declare that the article content was composed in the absence of any commercial or financial relationships that could be construed as a potential conflict of interest

Received 7 September 2015; accepted 10 December 2015 Citation: World Neurosurg. (2016) 88:370-373. http://dx.doi.org/10.1016/j.wneu.2015.12.086

Journal homepage: www.WORLDNEUROSURGERY.org Available online: www.sciencedirect.com

1878-8750/\$ - see front matter (C) 2016 Elsevier Inc All rights reserved.

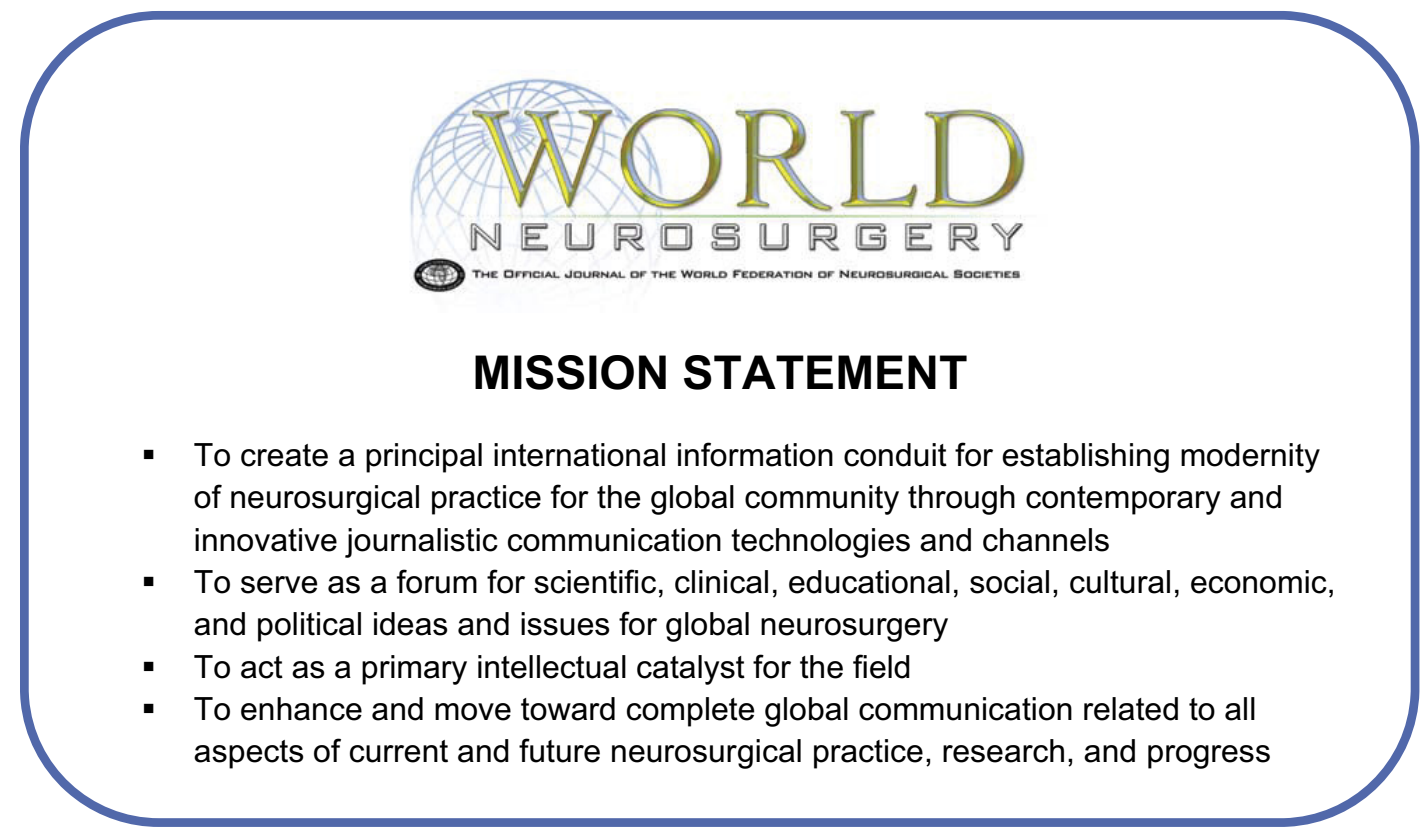

